\title{
DIRETRIZES DE TREINAMENTO REMOTO E COLABORAÇÃO
}

\author{
REMOTE TRAINING AND COLLABORATION GUIDELINES
}

\author{
Jairit Garavit ${ }^{2}$ \\ https://orcid.org/0000-0003-1976-9891
}

1. ¿Este produto é o resultado do trabalho árduo de uma de suas Linhas de Pesquisa do projeto "Como deve pesquisar em Educação virtual e a distância?" do ano de 2021, realizada com Membros de forma interdisciplinar e interinstitucional (Professores - Alunos) da Pesquisa Seedbed: Sistemas Integrados de Gestão "Integradoss" Anexados ao GrupLAC: SIGCIENTY da Universidade Nacional Aberta e a Distância UNAD.

2. Engenheiro Industrial, Especialista em Educação Superior e à Distância, Mestre em Sistemas Integrados de Gestão HSEQ-RSC, Revisor de Pares da Elsevier, Revisor de Pares da Publons Academy e Advisor \& Peer Rewiever de Mendeley, Editor de Currículo em Revistas Acadêmicas - Minciencias. Líder da Seedbed de Pesquisa "Integradoss" e nomeado Professor Pesquisador da Escola de Ciências Básicas, Tecnologias e Engenharia ECBTI. Zona Caribenha, na Universidade Nacional Aberta e a Distância - UNAD. Email institucional Jairit.Garavit@unad.edu.co

Projeto de Pesquisa: ¿Cómo pesquisar em Educação virtual e a distância?

Resumo: Incentivar os alunos a cooperar juntos em certas atribuições pode ajudar e dominar as concepções de ideias importantes e também expandir os tipos de habilidades colaborativas essenciais que são exigidas em várias esferas de trabalho ou treinamento. Embora o treinamento remoto exija alguns arranjos nas conveniências em que a colaboração tende a funcionar, uma vez que os alunos não estão fisicamente presentes no mesmo lugar, as representações síncronas e assíncronas da informação digital conseguem ser benéficas. Os exemplos de possíveis ações colaborativas podem variar de treinamentos conjuntos de brainstorming, demonstrações e objetivos conjuntos a interrogatórios virtuais realizados em sala de aula. 
Palavras-chave: Colaboração, Educação a Distância, Aprendizagem Remota, Habilidades Colaborativas.

Abstract: Encouraging students to cooperate together in certain assignments can assist and dominate insight into important insights and also expand the kinds of essential collaborative skills required in various spheres of work or training. Although remote training calls for some arrangements in the conveniences in which collaboration tends to work, since the learners are not physically present in the same place, both synchronous and asynchronous representations of digital information, manage to be of benefit. Examples of potential collaborative actions can range from joint brainstorming trainings, demonstrations and joint purposes to virtual interrogations conducted in the classroom. When collaboration becomes a central part of a remote training course, members are often more involved and can form an illustration of shared responsibility.

Keywords: Collaboration, Distance Education, Remote learning, collaborative attitudes

\section{Introdução}

Nos capítulos anteriores, mostramos que a colaboração difere da cooperação por exigir que o aluno tenha maior autonomia para exercer maior controle sobre sua aprendizagem. Ressaltamos também que as duas abordagens convergem tendo o compromisso com o grupo como valor fundamental. Em seguida, explicamos que, entre os aprendizes autônomos com capacidade de autogestão, a colaboração se dá por meio da conversação e se estabelece como modelo de comunicação. No entanto, vimos que, em ambientes colaborativos, o espaço de comunicação passa a ser central, organizando-se em locais de conversação, tele-gestão, tele-discussão, teletrabalho, tele-socialização e tele-assistência. Os alunos interagem com eles por escrito por meio de fóruns eletrônicos.

O sucesso destas trocas textuais, com as potencialidades e limitações que nelas reconhecemos, baseia-se, entre outras coisas, na participação voluntária e benevolente dos alunos, nos meios de comunicação aceites por todos, na conciliação das necessidades pessoais dos os estudantes. Com o objetivo que o grupo tem dado, sobre a motivação que deve ser genuína, sobre o sentimento de profunda satisfação por pertencer ao grupo e sobre a mais-valia que o grupo e o trabalho em grupo proporcionam. Já a animação é também um dos fatores de sucesso dos grupos virtuais. Sob a responsabilidade principal do treinador, a facilitação é baseada nos conhecidos princípios de facilitação de grupos presenciais aos quais é adicionado o "Know How" específico de facilitação de fóruns eletrônicos. 
Neste capítulo, apresentamos os fundamentos de um modelo de colaboração entre alunos e tratamos dos recursos colaborativos que são o grupo e das ferramentas tecnológicas presentes no ambiente de aprendizagem. O capítulo está dividido em três fragmentos que pertencem às três unidades básicas do guia de colaboração proposto: a comunicação de ideias dentro dos grupos, o empenho dos alunos e a coordenação das suas atividades. Em seguida, veremos como o grupo evolui para uma técnica de aprendizagem e ferramentas tecnológicas que podem apoiar o processo de aprendizagem e colaboração, e as ferramentas que iremos descrever são adicionadas ao espaço de comunicação e usadas em conjunto com fóruns eletrônicos.

\section{O todo e a colaboração}

$\mathrm{O}$ estudo da colaboração leva inevitavelmente a um interesse no grupo ou grupos, suas características e seu funcionamento. Por isso, é essencial saber o que se entende por grupo para lançar as bases de um modelo de colaboração e aprendizagem grupal.

\section{O que é um grupo?}

O grupo não é um conceito vago. A pesquisa em psicossociologia a define como uma entidade coletiva complexa e dinâmica, cuja atividade é governada por princípios operacionais. Um grupo não é um simples agrupamento de indivíduos, pois outras condições devem ser atendidas para que as pessoas formem um grupo. Para definir o que é um grupo, extraímos de vários autores a explicação da sua razão de ser e alguns princípios que nos ajudam a compreender o seu funcionamento.

Um grupo é definido principalmente pelo seu tamanho, pela correlação que se institui entre os membros e pelo propósito que os une. Grupos pequenos, que não ultrapassam 12 em número, e grupos grandes, que podem reunir cerca de 30 pessoas e até um pouco mais, não funcionam da mesma forma. Para ser eficaz, grupos grandes às vezes são divididos em subgrupos. Se quisermos facilitar a comunicação, estimular o compartilhamento, estimular o desenvolvimento de relacionamentos sólidos e estimular a interdependência. Mas, como sabemos, não basta colocar as pessoas na presença umas das outras para que exista um grupo, para que as relações se forjem e para que a vida coletiva se organize (St-Arnaud, 1989).

\section{Um grupo é mais do que um conjunto}

O agrupamento e o reagrupamento não são conceitos equivalentes, referem-se a dois tipos de encontros que respondem a expectativas diferentes. Como relata Damphousse (1996), grupos e reagrupamentos têm uma coisa em comum: compartilham o mesmo objetivo que satisfaz os interesses dos membros. O que os distingue é a interação entre os membros e as relações que se desenvolvem entre eles. No caso de reuniões, as relações humanas são geralmente superficiais. Os 
membros mostram inércia e passividade. Eles não estão dispostos a agir e iniciar ações conjuntas na condução de ações coletivas. Eles permitem que os organizadores, que são uma pequena minoria de membros, os representem, falem e ajam em seu nome. Em vez disso, o grupo reúne pessoas que querem se mobilizar por uma causa e que têm um objetivo comum.

Os membros do grupo têm tal percepção do objetivo que justifica e faz a exigência da cooperação ativa de todos os membros nas ações do grupo. Essa percepção do alvo comum, específico do grupo, não é imposta a todos espontaneamente. Quando o grupo nasce, o alvo pode ser difuso, mas se tornará uma realidade concreta e cada vez mais significativa graças às interações dos integrantes. O grupo deve dedicar tempo e meios para construir uma representação comum e se estabelecer firmemente na cultura do grupo.

O objetivo, ou meta comum, é a origem do grupo. Compartilhada e valorizada, expressa uma intenção e um propósito. No início, ao entrar em uma colaboração, o grupo ainda não tem objetivos formais e precisos. Estes, ao contrário do objetivo que representa o resultado a ser alcançado, especificam as tarefas a serem realizadas. Eles se tornarão gradualmente mais claros durante as trocas e negociações. Eles serão formulados de forma simples, mensurável e alcançável. Os objetivos coletivos, compatíveis com a razão de ser do grupo, podem também satisfazer objetivos individuais. Portanto, cada membro buscará atingir seus próprios objetivos por meio da ação em grupo. No entanto, o objetivo comum dos grupos de aprendizagem, que também têm um objetivo comum, é dividido em duas partes:

- O sucesso individual da atividade formativa em que o aluno participa;

- Aprenda com os outros (Damphousse, 1996).

Para que exista um grupo de aprendizagem, os alunos devem ter, além do desejo de sucesso, a vontade de participar e colaborar, ou seja, de participar das atividades grupais e aceitar o modo de atuação do grupo com suas recompensas e satisfações, mas também suas requisitos e limitações.

\section{Padrão de colaboração para grupos de aprendizagem}

O grupo é uma entidade viva que nasce, cresce, amadurece e morre. Seus estágios de desenvolvimento são conhecidos e amplamente documentados; eles já foram modelados por StArnaud (1989). No entanto, é-nos impossível, no âmbito deste trabalho, dar um relato exaustivo dos numerosos trabalhos relacionados com o grupo e o seu funcionamento. Limitamos nosso estudo ao processo colaborativo que ocorre dentro de um grupo. Lembre-se que nosso objetivo não é descrever o processo de crescimento de grupos de alunos, mas sim:

- Compreender como o trabalho intelectual se articula no seio de um grupo de alunos, já constituídos ou em processo de ser, que colaboram para aprender em ambiente virtual. 
- Identifique as demandas cognitivas deste trabalho intelectual.

- Descreva as ferramentas tecnológicas que podem ser úteis para eles.

Tomamos a existência do grupo como certa e tentamos modelar a atividade cognitiva, acima de tudo. Também estamos cientes de que não podemos esperar que alunos agrupados em um ambiente virtual atualizem espontaneamente o potencial do grupo para colaborar e aprender. Para isso, métodos e recursos devem ser implementados para que o grupo nasça, cresça e atinja uma certa maturidade.

Figura 3.1

\section{Dinâmica de colaboração}

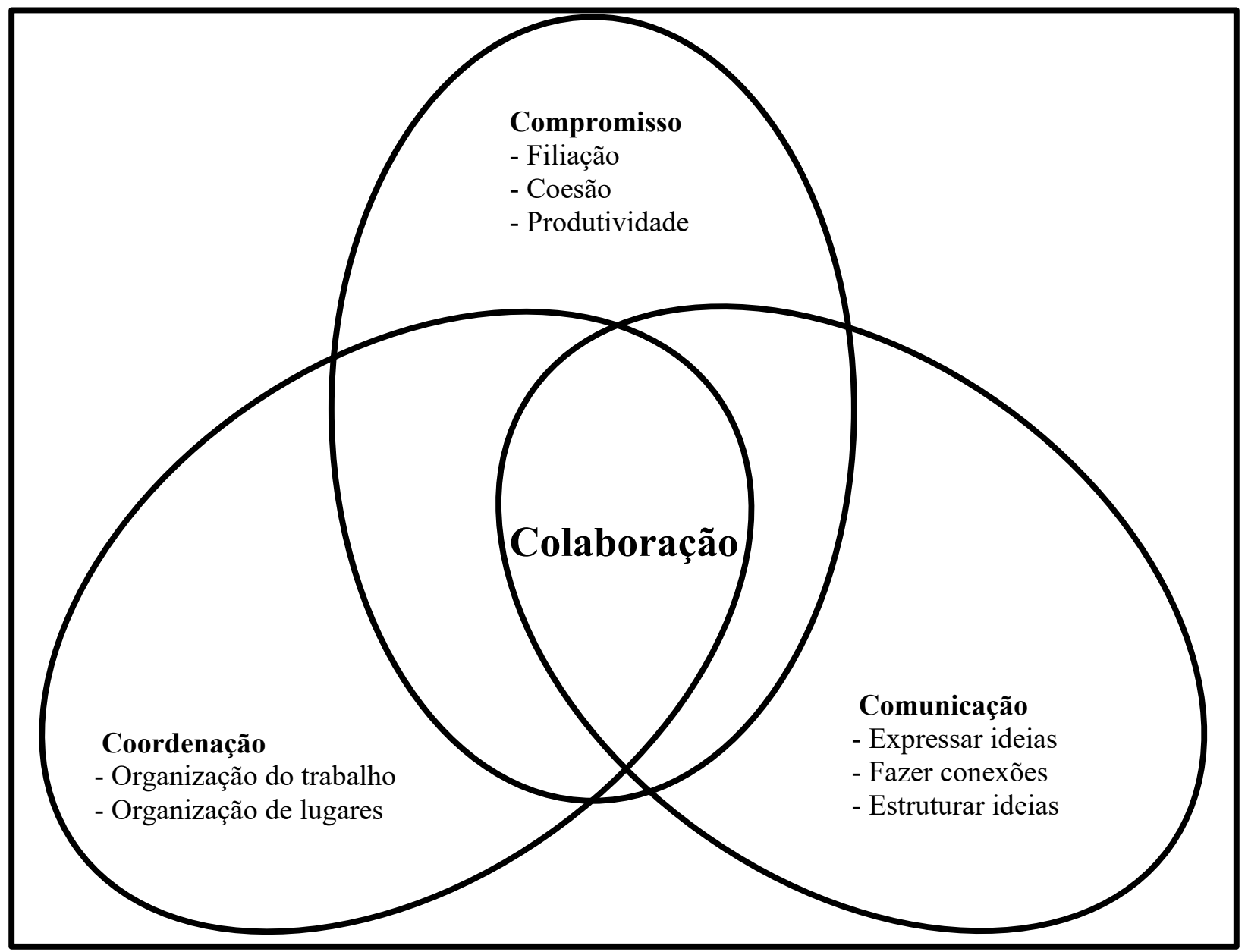

Garavit, J. 2021

\section{Elementos de tipo colaborativo}

Os alunos que optaram por ingressar em um grupo para aprender colaborativamente entenderam que devem participar ativamente das ações do grupo; quando param de participar, param de colaborar e o grupo deixa de existir: a comunidade de aprendizagem se dissolve. A participação é essencial para a vida em grupo e forma a base da colaboração. E, como explicamos nos tópicos 
anteriores, o processo de treinamento colaborativo dá ao aluno e ao grupo alguma liberdade. Eles devem se juntar ao grupo livremente e querer se comunicar para trabalhar e aprender juntos. A colaboração também requer o uso de métodos de gestão para coordenar a atividade do aluno, respeitando sua autonomia. Portanto, a colaboração é realizada da seguinte forma:

- A comunicação estimula a reflexão sobre o propósito de colaboração, conclusão de tarefas e construção de relacionamentos.

- Compromisso em garantir uma contribuição cognitiva e social significativa, colocando-se a serviço do grupo e mobilizando esforços para o sucesso.

- Coordenação para otimizar a eficiência da atividade do grupo.

Nós os descrevemos nas páginas a seguir e explicamos como eles funcionam em fóruns eletrônicos. Para cada componente, identificamos as ferramentas tecnológicas que podem apoiar o trabalho do grupo. Espera-se que esta descrição ajude os designers a imaginar as atividades e ferramentas colaborativas de um ambiente de aprendizagem virtual.

\section{Declaração de ideias}

\section{Tabela 3.1}

Dinâmica de ideias e atividades de comunicação

\begin{tabular}{|c|l|}
\hline $\begin{array}{c}\text { Dinâmica de ideias de } \\
\text { comunicação }\end{array}$ & \multicolumn{1}{c|}{ Exemplos de tarefas e atividades cognitivas } \\
\hline Expresse ideias para compartilhá- & $\begin{array}{l}\text { Participe de um brainstorming } \\
\text { Participe de uma discussão } \\
\text { Transmitir informação } \\
\text { Desenvolva ideias que foram apresentadas por outras } \\
\text { pessoas. } \\
\text { Questione-se e questione-se } \\
\text { Comente, critique e avalie } \\
\text { Tome uma posição }\end{array}$ \\
\hline Faça conexões entre ideias para \\
obter novas ideias. & $\begin{array}{l}\text { Analise as declaraços para depurá-las e extrair o essencial } \\
\text { Refletir, induzir, deduzir } \\
\text { Faça conexões entre conceitos, princípios, estratégias } \\
\text { Compare diferentes pontos de vista e ideias divergentes. }\end{array}$ \\
& $\begin{array}{l}\text { Identifique os campos teóricos e de aplicação e encontre os } \\
\text { fundamentos }\end{array}$ \\
\hline Estruture as ideias para que & $\begin{array}{l}\text { Organize ideias } \\
\text { Foçam sentido. }\end{array}$ \\
& $\begin{array}{l}\text { Desenvolizar ideias um mapa conceitual } \\
\text { Desenvolva um modelo de conhecimento }\end{array}$ \\
\hline
\end{tabular}

Garavit, J. 2021 
Em nosso modelo, a comunicação é abordada do ponto de vista cognitivo e está relacionada ao trabalho que os alunos realizam para compartilhar suas ideias e construir seus conhecimentos juntos. Quando o aluno participa de um processo colaborativo, ele se engaja em um processo de comunicação cognitiva que o leva a:

- Expresse ideias para compartilhar com o grupo.

- Faça conexões entre as idéias expressas (suas e de outras pessoas) para obter novas idéias.

- Estruturar as próprias ideias e as dos outros) para dar sentido a elas e construir conhecimentos.

Esse trabalho, que deve levar à construção de novos conhecimentos, é realizado em grupo por meio da elaboração de uma cadeia de ações ou tarefas cognitivas que são desenvolvidas em ordem crescente de complexidade. Os alunos são incentivados a pensar juntos para aprender juntos. $\mathrm{O}$ esforço cognitivo necessário aumenta com a progressão das trocas. De uma fase para a outra (expressão de ideias, estabelecimento de conexões entre ideias e estruturação de ideias), a complexidade cognitiva aumenta, assim como as necessidades cognitivas do aluno (Tabela 3.1). Nesta seção, tentamos identificar as necessidades cognitivas em relação à comunicação de ideias e descrever as ferramentas tecnológicas que o ambiente deve fornecer para satisfazê-las.

\section{Formule ideias para colaboração}

Em um processo de treinamento colaborativo, os alunos primeiro iniciam um processo de exploração que requer habilidades cognitivas e metacognitivas de alto nível. Eles começam esta exploração do objeto a ser conhecido expressando de uma forma coerente, significativa e compreensível para os outros, as idéias que vêm à mente sobre aquele objeto. Em seguida, eles questionam suas próprias ideias, expressam o que pensam e reagem aos comentários e feedback de seus colegas. Realizam pesquisas para identificar os limites e a estrutura do campo estudado e opinar sobre o conteúdo de suas leituras e sobre o pensamento dos autores consultados.

Este trabalho pode levar a conflitos cognitivos que você deve trabalhar para resolver. Para que a exploração seja viável e eficaz, os alunos devem ser capazes de encontrar informações relevantes suficientes sobre o objeto de estudo no ambiente. Além disso, o treinador fornecerá pistas e caminhos para reflexão que os levarão a explorar as diferentes facetas do tópico de estudo. Em suma, para estimular a expressão de ideias, os alunos precisam, acima de tudo, de informações e do apoio de uma pessoa competente para orientar suas pesquisas e facilitar suas discussões.

\section{Ambiente tecnológico}

O principal recurso tecnológico de apoio à expressão de ideias é, sem dúvida, o fórum eletrônico. O que se espera dessa ferramenta é que ela seja adequadamente maleável para permitir 
que atividades livres, espontâneas e não estruturadas, como o brainstorming, explorem o objeto a ser conhecido, dando rédea solta à expressão de ideias. Nesse caso, não é desejável que o software do fórum dite ou apoie uma estrutura para a discussão; então, só poderia impor restrições à fala e limitar a espontaneidade da comunicação.

Se o software do e-fórum não deve governar a estrutura das trocas, também deve permitir alguma organização. Para explorar um tópico ou área, devemos ser capazes de criar um fórum de discussão específico para cada uma das ideias fortes ou tópicos cruciais. A interface do software deve permitir que você visualize a estrutura desses fóruns e identifique os fóruns relacionados a cada um dos tópicos. Desta forma, o aluno poderá orientar-se na área de notificação e localizar facilmente o fórum adequado para publicar sua mensagem.

O software que conhecemos é bastante rudimentar. Para encontrar as ideias expressas em um fórum, eles oferecem funcionalidades limitadas que procedem da classificação: classificação por tópico de discussão, por tópico de mensagem, por data de postagem, por autor e por tipo de documento. Por outro lado, são bastante amigáveis, fáceis de aprender, fáceis de usar e suas interfaces permitem um manuseio intuitivo dos comandos. Softwares que não possuem essas funções básicas de detecção de ideias e usabilidade mínima não podem ser aceitos, especialmente quando os alunos estão em suas primeiras experiências de comunicação telemática.

\section{Conexões entre ideias}

Por meio da exploração coletiva de um tema ou domínio, os alunos são levados a realizar um processo de reconstrução da informação por meio de análise, comparação, indução e dedução. Eles fazem conexões entre ideias e desenvolvem inferências que levam ao desenvolvimento de microestruturas. Estas microestruturas, que vão se construindo ligando ideias, conduzem à formação de novos conceitos e dão origem a uma primeira percepção do campo e dos seus limites. Para conectar as ideias expressas umas às outras e organizá-las em uma estrutura, os alunos trabalham em um conjunto volumoso de mensagens nas quais as opiniões de seus colegas são expressas. Em seguida, eles enfrentam dois problemas: o do volume de informações a serem processadas e sua complexidade.

\section{Recursos do ambiente de tecnologia}

Para processar eficazmente as informações contidas nos fóruns eletrônicos, fazer conexões entre ideias e estimular o surgimento de novos conceitos, os alunos devem ser capazes de consultar as mensagens de forma rápida e fácil e ter uma visão completa, mas resumida ou condensada do que foi publicado. dizendo. Eles devem encontrar funcionalidades no ambiente que permitam: 
- Acesso e recuperação de informações para identificar ideias contidas no banco de mensagens.

- Classificação e classificação de mensagens para agrupar ideias.

- A anotação para fornecer pontos de referência.

- Crie ligações entre ideias.

Primeiramente, vamos enfatizar que essas funções devem estar acessíveis offline, na estação de trabalho do aluno, para que eles possam trabalhar em paz com o registro da mensagem. As funções de acesso e recuperação de informações devem permitir:

- Leitura rápida de mensagens.

- Acesso a resumos ou resumos de intervenções.

- Pesquise por meio de pesquisas de texto.

Uma vez localizada a informação, o aluno deve ser capaz de fazer um agrupamento inicial de ideias com uma ferramenta de classificação e, em seguida, usar ferramentas de anotação para registrar suas observações e comentários nas ligações entre as ideias. Essas notas podem ser usadas para desenvolver novas ideias, escrever outras mensagens para postar nos fóruns ou produzir documentos a serem postados em áreas comuns. Também deve ser possível usar ferramentas do tipo hipertexto para criar links entre os segmentos de mensagem a serem associados e obter representações na forma de redes e mapas semânticos e conceituais que podem ser compartilhados com o grupo (Klemm e Snell, 1996).

\section{Estruture ideias com significado}

A estruturação de ideias permite a construção de conjuntos nocionais completos e coerentes a partir das microestruturas desenvolvidas pelos alunos. Consiste no desenvolvimento de macroestruturas (Deschênes, 1995) que podem ser organizadas de acordo com diferentes modelos: lógico, argumentativo, descritivo, narrativo, etc. O modelo escolhido corresponderá ao objeto, finalidade e contexto da aprendizagem.

Ao manipular as ideias dessa forma, o aluno se apropria do objeto de estudo; ele o reconceitua e desenvolve uma compreensão mais profunda dele. Este processo individual é seguido por agrupamento. Por sua vez, o grupo se apropria do objeto de estudo de forma original por meio da discussão, negociação e consenso.

O resultado deste trabalho pode assumir várias formas: declarações de princípios, uma declaração de posição comum, definições, um texto teórico, um hipertexto, uma rede semântica, um mapa conceitual, etc. Para alcançar tais produções, os alunos precisam de uma supervisão que 
será mais ou menos estruturada de acordo com seu domínio da área, sua autonomia e seu conhecimento dos métodos de trabalho em grupo.

Tabela 3.2

\section{Estruturação de ideias}

\begin{tabular}{|c|l|}
\hline Elemento de estratégia & \multicolumn{1}{c|}{ Descrição } \\
\hline Produção em grupo. & $\begin{array}{l}\text { Um mapa conceitual organizado de acordo com uma estrutura } \\
\text { lógico, argumentativo, narrativo, descritivo ou outro. }\end{array}$ \\
\hline \multirow{3}{*}{ Material de apoio. } & $\begin{array}{l}\text { Guia de produção de mapa conceitual que inclui: } \\
\text { - Regras de construção para diferentes modelos de cartão } \\
\text { - Métodos de trabalho individual e coletivo } \\
\text { Ferramentas de software usadas para produção } \\
\text { Guia e instruções para trabalho em equipe }\end{array}$ \\
\hline \multirow{5}{*}{ Distribuição de funções. } & $\begin{array}{l}\text { As funções visam esclarecer as ideias expressas, } \\
\text { estruturá-los e compartilhá-los com o grupo. } \\
\text { Coordenador: garante que cada membro execute } \\
\text { suas tarefas na hora; comentar os documentos apresentados pelos } \\
\text { membros do grupo; veja se o trabalho corresponde ao objetivo que o } \\
\text { grupo ou equipe estabeleceu. } \\
\text { Editor de lista de conceitos:consolidar e editar as listas de conceitos e } \\
\text { princípios produzidos por cada membro; produz uma lista resumida e a } \\
\text { compartilha com o grupo. } \\
\text { Motor de busca de informações: enriquece a lista de resumo, ajudando } \\
\text { os editores a encontrar as informações que faltam. } \\
\text { Editor de mapa conceitual:A partir da lista de resumo, construa um } \\
\text { mapa conceitual mostrando os links e a estrutura; Encaminha para o } \\
\text { grupo para discussão, melhoria e validação. }\end{array}$ \\
\hline
\end{tabular}

Garavit, J. 2021

Portanto, o uso de dramatizações para desenvolver um mapa conceitual é um exemplo de estratégia de coaching ou orientação que pode ser aplicada para apoiar o processo de estruturação da ideia. Resumiram na tabela 3.3 os elementos de uma dramatização de papéis idealizada por Klemm e Snell (1996) para fazer com que um grupo de alunos produzisse um mapa conceitual do objeto de aprendizagem.

Os alunos devem ser capazes de acessar dispositivos offline para construir mapas, planos ou templates que permitam visualizar, de uma perspectiva de nível superior, a macroestrutura ao indicar as microestruturas, ou seja, os vínculos que foram estabelecidos entre as ideias dentro dos bancos de mensagens. As ferramentas que se prestam ao desenvolvimento dessas estruturas são as ferramentas de modelagem de conhecimento, as ferramentas de hipertexto, os mapas conceituais e as ferramentas que auxiliam no desenvolvimento de um plano. Eles devem ser capazes de processar todas as mensagens de forma transparente e ser fáceis de usar. 
Figura 3.3

Modelo de conhecimento

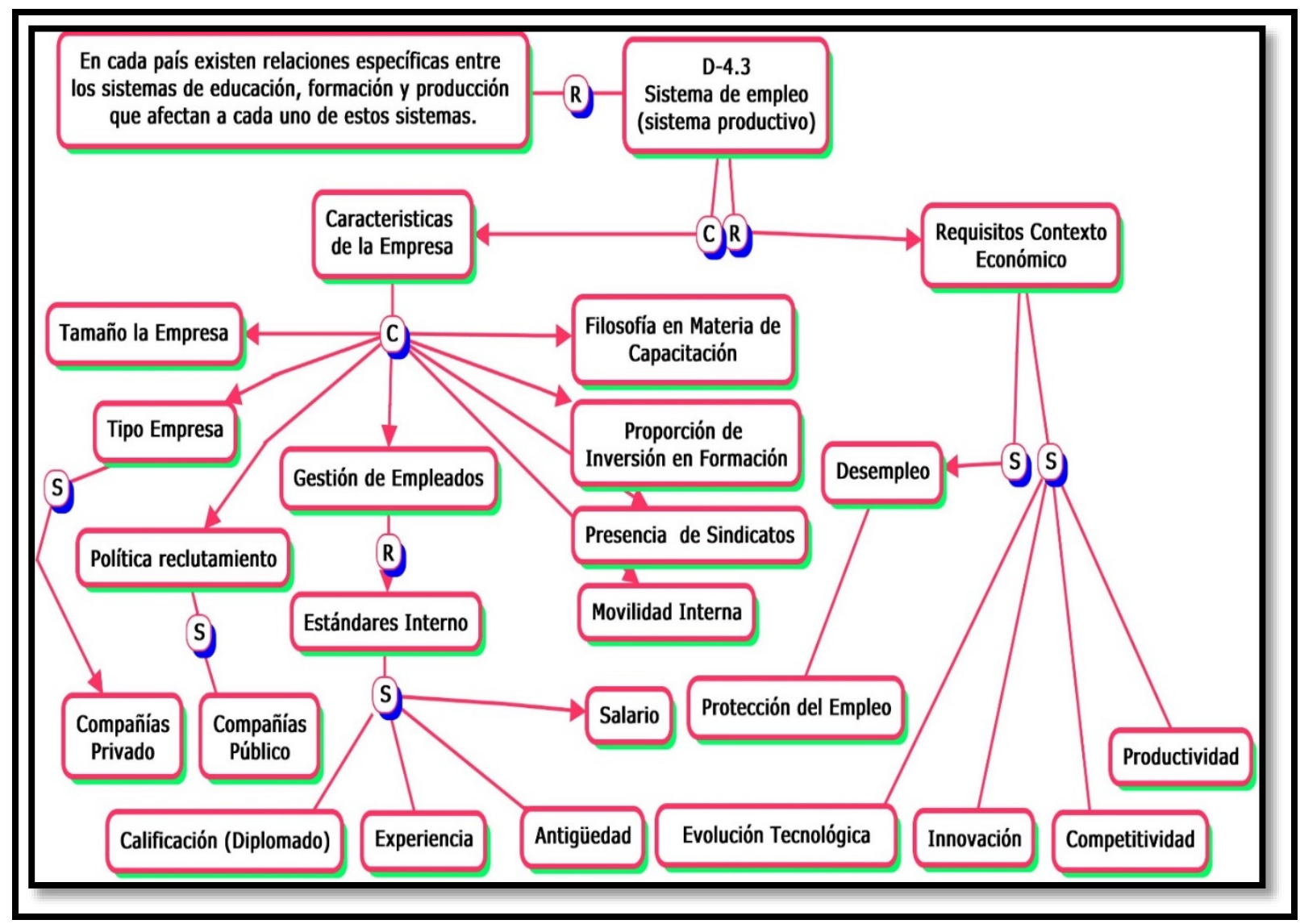

Garavit, J. 2021

\section{Ferramentas de modelagem de conhecimento.}

Existem ferramentas especializadas de estruturação de conhecimento que determinam e controlam a estrutura do objeto que queremos representar ou modelar. Essas ferramentas podem pegar ideias, combiná-las e organizá-las de acordo com regras precisas. Eles permitem identificar o tipo de vínculo entre as ideias, princípios, procedimentos e fatos que compõem o modelo de conhecimento: vínculos de composição, regulação, precedência, etc., como no exemplo a seguir. Eles são ferramentas reais para ajudar o pensamento humano (ver figura 3.3).

Estruturas de projeto: coletar e estruturar informações. Paquin (1993) explica que a coleção permite agrupar um conjunto de unidades de informação para criar agregados com propriedades como agregados. A estruturação da informação reúne todas as operações suportadas pela administração da distribuição dos documentos e múltiplas visões sobre essas estruturas. 
Independentemente de terem sido pensados para auxiliar quem deseja trabalhar na estruturação de um objeto de conhecimento, esses mecanismos presentes nos sistemas de hipertexto podem auxiliar o aprendiz no processo de estruturação de ideias.

O hipertexto continua a evoluir devido à extensa exploração passada por designers de interfaces para a Internet. Devemos acompanhar esses desenvolvimentos de perto e considerar a adição de ferramentas de hipertexto aos fóruns eletrônicos. Essa integração deve permitir que cada mensagem ou conjunto de mensagens seja considerado um nó endereçável e navegue facilmente de um ponto a outro.

A ferramenta de hipertexto deve facilitar:

- Consulta a toda a rede de bancos de mensagens, utilizando links para aceder e consultar a informação destes nós.

- O desenho de estruturas, através do estabelecimento de novas ligações entre esses nós.

- O layout de documentos armazenados na forma de nós e vinculados a mensagens relacionadas.

A Figura 3.4 mostra o aparecimento de outro mapa conceitual e hiperlinks que teriam sido produzidos. Mapas conceituais, existem ferramentas especializadas para construir mapas conceituais; possibilitar a organização de informações lineares em uma representação espacial que indique.

Figura 3.4

Mapa conceitual e links de hipertexto

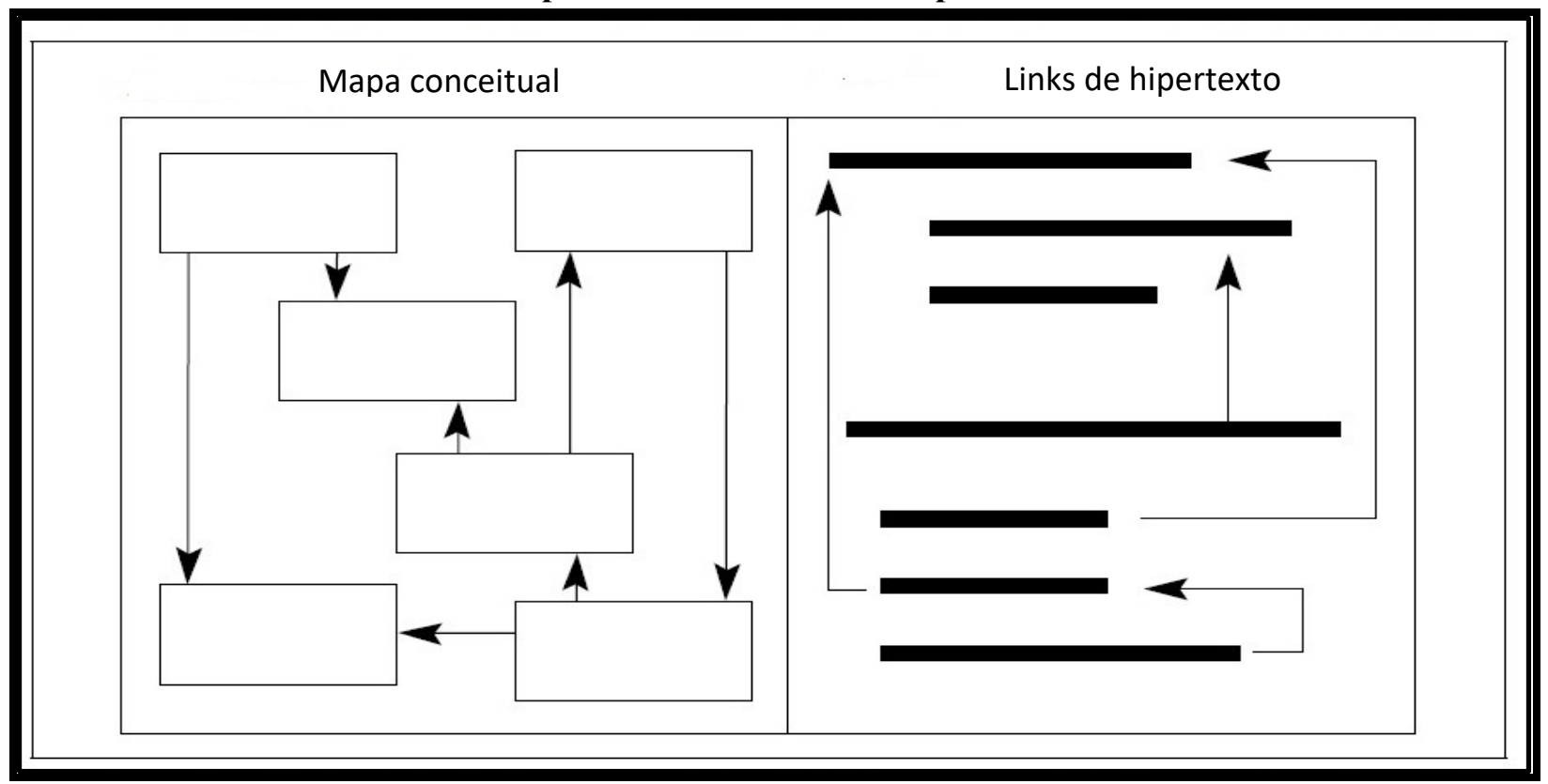

Garavit, J. 2021. 
As ligações e relações entre ideias ou conceitos. Eles fornecem uma organização hierárquica, colocando conceitos mais comuns no topo do mapa e conceitos concretos na parte inferior. Os links são nomeados para unir unidades semânticas. Esses mapas semânticos são usados principalmente como ferramentas de negociação de significados na fase de construção do conhecimento (Schroeder e Kenny, 1995).

No entanto, eles também podem ser usados na fase inicial de exploração para reunir ideias e começar a fazer conexões e delinear os limites do tópico. Eles relatam que os mapas conceituais são geralmente muito populares entre os alunos e beneficiam principalmente aqueles que os constroem. Acrescentam que os cartões elaborados pelos formadores só podem ajudar os formandos se estes já tiverem tido a oportunidade de os desenhar eles próprios.

Uma ferramenta de hipertexto ou ferramenta de mapeamento de conceito pode ser um recurso de aprendizagem pobre se o aluno não souber como usá-la. A pesquisa mostrou que para usar uma ferramenta de hipertexto de forma eficaz, o usuário deve saber fazer anotações e desenvolver um plano. Portanto, parece apropriado ajudar os alunos a exibir suas habilidades de anotações e planejamento para que possam tirar proveito das ferramentas de hipertexto que seriam integradas ao software do fórum eletrônico ou oferecidas em paralelo.

\section{Ferramentas de suporte para anotações.}

Fazer anotações pode servir a três funções: codificar informações brutas durante ou depois de ler, ouvir ou assistir a uma apresentação; preparar um documento a ser consultado para lembrar e memorizar informações; reconstruir informações ao fazer anotações depois de ler, ouvir ou ver. As ferramentas para fazer anotações são geralmente estruturadas de maneira livre. Eles permitem que o usuário faça anotações pessoais, mas também copie e cole informações extraídas de um documento. Embora as notas pessoais exijam um esforço de análise e síntese, a função de copiar e colar requer apenas a escolha das informações. Para ajudar a desenvolver estratégias pessoais de anotações, escolheremos uma ferramenta que permite ao aluno revisar as informações anotadas de diferentes pontos de vista (lista de ideias fortes, ideia forte e ideias relacionadas, ligações que foram estabelecidas entre as ideias, etc.) e reorganizá-lo adicionando outras informações (Röscheisen, Mogensen e Winograd, 1996).

\section{Ferramentas para auxiliar no desenvolvimento de um plano.}

Saber fazer um plano é uma habilidade de alto nível. Deve-se ser capaz de identificar as relações entre idéias e conceitos e organizá-los em uma ordem de subordinação. Este processo destaca os pontos importantes e essenciais de um conteúdo, ajuda a familiarizar-se com a estrutura de um domínio ou documento, reter informações e reorganizá-las em uma ordem significativa. Seria 
desejável fornecer uma ferramenta para ajudar a desenvolver um plano que pudesse funcionar em vários formatos de documento (doc, ppt, html, pdf etc.) e em anotações pessoais feitas em um documento.

\section{Compromissos adquiridos com o grupo}

Acabamos de examinar os principais mecanismos de comunicação cognitiva, o primeiro componente de um modelo colaborativo, e descrevemos brevemente as ferramentas tecnológicas para apoiá-los. Passamos agora ao estudo do compromisso com o grupo que os alunos devem liderar. Vemos o compromisso como uma disposição emocional e psicológica sem a qual a colaboração não pode ser concebida. $\mathrm{O}$ comprometimento se reflete na colaboração participativa de todos os membros de um grupo e em esforços genuínos para completar tarefas e atingir a meta. A dinâmica sócio-cognitiva que prevalece dentro de um grupo pode estimular, encorajar ou mesmo desestimular o engajamento. Pesquisa sobre aprendizagem em grupo. (Abrami et al., 1995) permitiu a identificação de três variáveis de compromisso: pertencimento ao grupo,

\section{Membros do grupo}

\section{Tabela 3.3}

\section{Conscientização associada ao treinamento colaborativo}

\begin{tabular}{l}
\hline \multicolumn{1}{|c|}{ Consciência do grupo como ambiente social } \\
\hline O que posso esperar de outros membros do grupo? \\
Como vou interagir com este grupo? \\
Que papel vou assumir no grupo? \\
Que papel os outros membros da equipe assumirão? \\
\hline \multicolumn{1}{c|}{ Conscientização da natureza cognitiva da tarefa e suas demandas. } \\
\hline O que eu sei sobre o tópico e a estrutura da tarefa? \\
O que outras pessoas sabem sobre o tópico e a tarefa? \\
Quais são as etapas que teremos que concluir para concluir a tarefa? \\
Como os resultados serão avaliados? \\
Quais ferramentas e materiais são necessários para concluir a tarefa? \\
Quanto tempo leva o trabalho? Quanto tempo nós temos? \\
\hline \multicolumn{1}{c|}{ Conscientização das necessidades cognitivas relacionadas à tarefa. } \\
\hline Como essa tarefa se encaixa no que já sei? \\
O que preciso aprender relacionado ao assunto? \\
Quais informações eu preciso? \\
Preciso revisar minha percepção e ideias à luz das notícias? \\
em formação? \\
Até onde sei, posso ver os resultados da tarefa? \\
\hline \multicolumn{1}{c|}{ Conscientização do espaço comum e uso compartilhado de recursos. } \\
\hline O que os outros membros do grupo devem fazer para completar a tarefa? \\
O que fazem eles? No que você está trabalhando atualmente? \\
O que eles já alcançaram? \\
O que eles farão a seguir? \\
Como posso ajudar outros alunos em relação ao dever de casa? \\
\hline
\end{tabular}


A adesão é revelada pelos esforços manifestos dos alunos para se envolverem no trabalho do grupo. Um sentimento de pertença se desenvolve neles quando sentem que deram uma contribuição real para a realização do objetivo comum e sentem que obtiveram um benefício pessoal inestimável dele (Schragé, 1990).

Segundo Gutwin, Stark e Greenberg (1995), o sentimento de pertença, elemento fundamental para o sucesso da colaboração, é mais difícil de ser instalado em grupos virtuais devido à pobreza de canais de comunicação que permitem apenas pouca informação contextual e pouca informação física, reforço social ou comportamental. No entanto, o sentimento de pertença pode ser estimulado por quatro realizações:

- O aspecto social da colaboração: Essa conscientização tem como objetivo neutralizar a impressão de estar sozinho trabalhando em frente a um computador e aumentar a consciência sobre as limitações do trabalho em grupo e as expectativas de participação que ele cria.

- A natureza cognitiva da tarefa: Essa conscientização quer ajudar o aluno a compreender que são seus recursos cognitivos que ele deve utilizar e que canalizando seus esforços na mesma direção em que o grupo participará do sucesso da tarefa.

- Necessidades cognitivas relacionadas ao dever de casa: Essa conscientização visa ajudar o aluno a gerenciar e regular sua aprendizagem e valorizar seu progresso.

- Espaço comum e compartilhamento de recursos: Essa conscientização visa ajudar o aluno a compreender que compartilha um universo mental com seus colegas e que deve apoiá-lo no alcance do objetivo comum, fazendo com que ele se beneficie de seus recursos.

O treinador pode promover essas percepções fazendo perguntas como as apresentadas na Tabela 3. 3 e usando várias estratégias que resumimos na Tabela 3.4.

Para desenvolver um sentimento de pertencimento, os alunos precisam perceber a presença de outras pessoas no ambiente e se perceber no grupo. Eles também precisam saber quem está fazendo o que, para valorizar o esforço dos outros, medir a qualidade e a quantidade do trabalho realizado pelo grupo e garantir que o compromisso seja mútuo. Precisando desenvolver um entendimento compartilhado, trabalhando juntos em um espaço comum, compartilhando seus recursos e ajudando uns aos outros.

Os recursos ambientais devem informar especificamente os alunos sobre a sua própria contribuição para o trabalho em grupo e sobre a atividade em grupo. Essa necessidade pode ser satisfeita pela visualização ou representação de objetos relacionados aos participantes, conteúdo, tarefa, interações, recursos, etc. Além disso, como já mostramos, os alunos devem ser capazes de 
evoluir em espaços de trabalho virtuais especialmente concebidos, onde possam trocar, interagir e trabalhar juntos para realizar a tarefa.

Tabela 3.4

Sensação de pertencer

\begin{tabular}{|c|c|}
\hline Consciência & Intervenções Educacionais \\
\hline $\begin{array}{l}\text { Aspecto social da } \\
\text { colaboração e forma de } \\
\text { trabalhar. } \\
\text { Os alunos formam um grupo, } \\
\text { compartilham um objetivo } \\
\text { comum. } \\
\text { Eles trabalham juntos e } \\
\text { podem contar com o apoio } \\
\text { do grupo. }\end{array}$ & $\begin{array}{l}\text { - Convide os alunos a se apresentarem para se conhecerem melhor. } \\
\text { - Peça-lhes que compartilhem suas motivações, expectativas e necessidades. } \\
\text { - Fornecer informações sobre a composição e perfil do grupo. } \\
\text { - Publicar as informações de contato do aluno para facilitar as comunicações } \\
\text { sociais informais. } \\
\text { - Lembre-se do objetivo comum de fortalecer o consenso. } \\
\text { - Incentive os alunos a validar seus conhecimentos com o grupo. } \\
\text { - Incentive trocas sobre o significado, utilidade e } \\
\text { relevância social do conhecimento adquirido. } \\
\text { - Faça ligações pedindo ajuda. } \\
\text { - Identificar recursos e habilidades dentro do grupo. } \\
\text { - Garantir a complementaridade de funções para a realização de tarefas comuns. }\end{array}$ \\
\hline $\begin{array}{l}\text { Natureza cognitiva da } \\
\text { tarefa e seus requisitos. } \\
\text { A tarefa é manipular idéias e } \\
\text { conceitos abstratos; requer } \\
\text { habilidades cognitivas e } \\
\text { metacognitivas de alto nível. }\end{array}$ & $\begin{array}{l}\text { - Explique claramente os requisitos da tarefa colaborativa: } \\
\text { - as habilidades necessárias, incluindo aquelas a serem desenvolvidas, } \\
\text { - a participação esperada, } \\
\text { - investimento pessoal, } \\
\text { - as limitações do trabalho de grupo intelectual. } \\
\text { - Dê conselhos metodológicos. } \\
\text { - Reconhecer contribuições e esforços individuais. } \\
\text { - Mostrar como as contribuições cognitivas de cada } \\
\text { Contribuir para a realização do objetivo comum. }\end{array}$ \\
\hline \begin{tabular}{l}
\multicolumn{3}{c}{ Necessidades cognitivas } \\
\multicolumn{3}{c}{ relacionadas à tarefa. } \\
Os alunos revisam suas \\
realizações, avaliam os \\
deveres de casa e \\
desenvolvem estratégias \\
para realizá-los.
\end{tabular} & $\begin{array}{l}\text { - Fornecer ferramentas de autoavaliação. } \\
\text { - Fornecer ferramentas de autogerenciamento. } \\
\text { - Apresentar e discutir habilidades metacognitivas. } \\
\text { - Sensibilize o pensamento reflexivo. }\end{array}$ \\
\hline $\begin{array}{l}\text { Espaço comum, } \\
\text { compartilhamento de } \\
\text { recursos. } \\
\text { Colaborar é desenvolver um } \\
\text { entendimento compartilhado } \\
\text { em um espaço virtual } \\
\text { comum. }\end{array}$ & $\begin{array}{l}\text { - Deixe que todos aprendam sobre o trabalho realizado. } \\
\text { - Convide os alunos a compartilhar recursos, trocar seus trabalhos, compará-los } \\
\text { e comentar com o propósito de ajudar e aprender. }\end{array}$ \\
\hline
\end{tabular}

Garavit, J. 2021

\section{Medidas sociométricas.}

As ferramentas de análise de rastreamento podem gerar representações visuais da colaboração. Os parceiros gramaticais, por exemplo, são úteis para o aluno saber o que acontece dentro do grupo, apreciar a dinâmica das trocas e ter uma ideia do grau de comprometimento de cada um. Esse tipo de representação pode ser obtido por meio de dispositivos automatizados de medição sociométrica integrados ao software do fórum eletrônico. A Figura 3.4 fornece um exemplo de sociograma no qual podemos observar que o aluno B interage pouco com o grupo. 
Essas informações podem ser úteis para diagnosticar um problema de funcionamento dentro do grupo, mesmo em um estágio inicial. O treinador pode então planejar intervenções, por exemplo, para melhorar o clima, estimular a participação ou mesmo ajudar o aluno a participar mais ativamente. Quando essas representações são acessíveis aos alunos, é aconselhável preservar o anonimato como no exemplo a seguir.

Figura 3.4

Interações de grupo de alunos

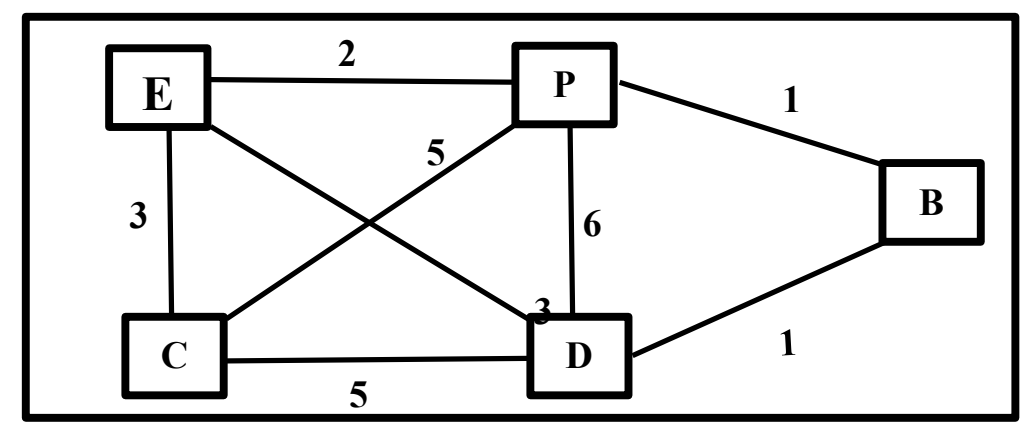

Garavit, J. 2021

\section{Áreas de trabalho virtuais}

A abordagem colaborativa convida os alunos a participarem de uma série de tarefas coletivas e individuais. Consequentemente, o ambiente não deve apenas oferecer as ferramentas adequadas para realizá-las, mas também incluir espaços de trabalho para a realização de cada tipo de tarefa. O aluno deve ser capaz de navegar facilmente de um espaço para outro, sentir que não está sozinho ao ocupar esses espaços e ser capaz de observar que outros também estão trabalhando na tarefa (Gutwin et al., 1995).

A partir de uma metáfora efetiva, as interfaces devem facilitar a orientação nos diferentes espaços, permitir saber quem está presente e quem veio, e indicar onde está o processo colaborativo. Portanto, o ambiente deve facilitar o direcionamento para links de informações embutidos sobre a situação colaborativa que podem ajudar o grupo a continuar seu trabalho. Quem faz ou fez o quê, quando e como (gerenciamento de tarefas)? Quais são os resultados da tarefa e os produtos resultantes? Em que espaço eles foram colocados (compartilhamento de recursos)? Quais produções aguardam comentários (discussão, negociação, consenso)? Onde está o grupo e onde estão as equipes do calendário? 


\section{Conexão e criação}

Como mencionamos anteriormente, coesão e produtividade são conceitos úteis para descrever o funcionamento de um grupo virtual ou presencial e o comprometimento dos alunos com o grupo. Aqui, veremos a correlação entre os dois. A ausência de outros comportamentos percebidos negativamente geralmente revela boa coesão dentro do grupo. Um exemplo dessa combinação de comportamentos é dado na Tabela 3.5.

Tabela 3.5

Comportamentos que indicam coesão do grupo

\begin{tabular}{|c|c|}
\hline $\begin{array}{c}\text { PRESENÇA } \\
\text { (comportamentos percebidos afirmativamente) }\end{array}$ & $\begin{array}{c}\text { AUSÊNCIA } \\
\text { (comportamentos percebidos negativamente) }\end{array}$ \\
\hline Compartilhe novas informações. & Domine a discussão. \\
\hline Faça perguntas para entender melhor. & Criticar. \\
\hline Dê explicações. & Para ser competitivo. \\
\hline Dê exemplos. & Fique na defensiva. \\
\hline $\begin{array}{l}\text { Comece a discussão sobre um novo tópico que } \\
\text { realmente funcionará. }\end{array}$ & Seja hostil. \\
\hline Expresse-se com humor na hora certa. & Ser mau. \\
\hline $\begin{array}{l}\text { Forneça feedback positivo sobre as contribuições de } \\
\text { seus colegas. }\end{array}$ & Seja sarcástico. \\
\hline
\end{tabular}

Garavit, J. 2021

À medida que cada grupo desenvolve sua própria cultura, os mesmos comportamentos podem ser percebidos de maneira diferente de um grupo para outro. Em um grupo, isso será julgado como um comportamento desejável e cuja presença seja positiva, pode ser percebida como indesejada ou negativa por outra pessoa. Portanto, para estimular e manter a coesão, é útil que os alunos conheçam as percepções do grupo para que possam adaptar seus comportamentos em conformidade.

Ao trabalhar com grupos de jovens face a face, Kagan (1992) observou que é possível estimular a coesão do grupo. Eles oferecem aos educadores a oportunidade de organizar o aumento de sócios, cujo objetivo explícito é fazer com que o grupo se conheça e entenda como trabalhar em conjunto (por exemplo, atividades de divulgação; atividades de valorização que levam ao desenvolvimento de interdependência positiva; atividades normativas para definir uma meta ou formular regras de participação, etc.). É preciso reconhecer, porém, que essas intervenções demoram muito e que só depois de muita discussão é que o grupo chega lá. Com os grupos virtuais, determinados materiais podem ser disponibilizados aos alunos para ajudá-los a se conhecerem e a desenvolverem coesão.

\section{A produtividade}


Avaliar a produtividade de um grupo também é uma questão de percepção: a percepção dos alunos sobre a colaboração como um meio de atingir o objetivo comum e seus objetivos pessoais. Collings e Walker (1995) descobriram que quando o objetivo comum é confuso, o grupo não sabe realmente o que está fazendo ou para onde suas atividades o levarão.

A coesão se deteriora e o grupo não se sente produtivo. Esses autores concluem que, para evitar uma situação que comprometa a colaboração e estimule a produtividade, os grupos precisam articular e negociar o objetivo comum e conciliar as expectativas dos membros. Por sua vez, propõem influenciar a percepção da produtividade atribuindo pontuações de grupo em vez de pontuações individuais. Esse método, usado com alunos jovens, não tem o mesmo efeito em alunos maduros e independentes. Com este último, seria melhor negociar o objetivo e a tarefa a ser realizada e acordar as modalidades precisas de realização: quem faz o quê, quando, como, com o quê, etc. Os participantes teriam então todos os dados em mãos para avaliar a produtividade real do grupo (Lundgren, 1996;).

\section{Coesão e produtividade}

Foi demonstrado que a coesão e a produtividade estão intimamente relacionadas e influenciam uma à outra. A coesão é o resultado de quatro fenômenos: o poder de atração do grupo sobre os participantes; o interesse da tarefa em questão; o compromisso com o cumprimento da tarefa e o orgulho coletivo que emana do grupo. Eles descobriram que o compromisso com a tarefa em mãos é a variável mais importante em coesão e produtividade. Tem um efeito positivo no desempenho do grupo e as informações que o grupo recebe sobre este desempenho influencia positivamente a sua coesão. Além disso, a correlação se aplica ainda mais quando se trata de pequenos grupos.

Figura 3.6

\section{Coesão e produtividade do grupo}

\section{Coesão}

- Atração

- Orgulho coletivo

- Interesse e compromisso

- Troca eficiente e criativa

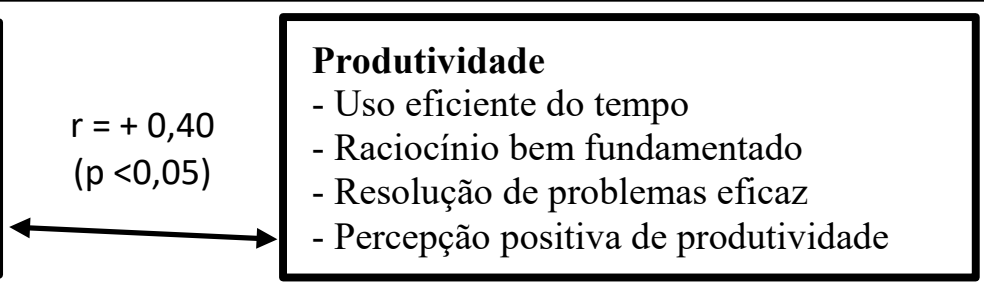

Garavit, J. 2021

Abrami e colegas (1995) desenvolveram um método para informar o grupo sobre seu desempenho usando índices de produtividade. Projetado para situações face a face, este método convida os alunos a preencher questionários durante e após as sessões de trabalho sobre sua percepção de coesão e produtividade do grupo. Mantendo o anonimato dos entrevistados, os resultados são apresentados ao grupo. Esses pesquisadores observaram que essa estratégia induz os alunos a tomarem consciência do funcionamento do grupo e os leva a refletir sobre sua forma 
de colaboração. Esta reflexão afecta o funcionamento do grupo e tem como efeito melhorar o clima do aluno, as condições de aprendizagem, a coesão e a produtividade.

\section{Fontes do ambiente tecnológico}

Pesquisas sobre a coesão e produtividade de grupos de alunos nos levam a postular que para otimizar o treinamento colaborativo a distância, os ambientes virtuais de aprendizagem devem integrar ferramentas de socialização e monitoramento de tarefas, além de instrumentos de medição, coesão e produtividade. Para estimular a coesão, podemos fornecer ferramentas que irão facilitar e até estimular a socialização.

Aqui estão alguns exemplos.

- Um diretório de participantes com os dados de contato de cada um informará os participantes sobre a composição e o tamanho do grupo (Quem são meus colegas?).

- A forma de cartão de visita que cada um preenche para se apresentar ao grupo (objectivos, aspirações, interesses e meios para se juntar a eles, etc.) irá facilitar os primeiros contactos, estimular o interesse mútuo e promover o sentimento de interdependência (poder de atracção dos grupo).

- Um espaço para currículos pode facilitar a formação da equipe e ajudar a avaliar as habilidades e a complementaridade dos membros do grupo (rede de apoio).

- Um espaço de socialização conversando sobre qualquer coisa contribui para o estabelecimento de um ambiente saudável e de camaradagem (sentimento de pertencimento).

Para ajudar os alunos a avaliar a produtividade do grupo, podemos oferecer ferramentas de rastreamento de projetos que mostram claramente o progresso do dever de casa. Várias ferramentas de medição automatizadas (questionários eletrônicos, ferramentas de votação, mecanismos de votação, etc.) também podem ser disponibilizadas para os alunos e módulos podem ser fornecidos para ajudar a interpretar os resultados. Para construir esses instrumentos, podemos nos inspirar naqueles que foram desenvolvidos para estudar a coesão e a produtividade do grupo (ver os instrumentos desenvolvidos por Abrami et al., 1995 e Dimock, 1985). Esses instrumentos são inventários de comportamentos apresentados.

Tabela 3.6

Resultados da avaliação de produtividade

\section{Para o desenvolvimento de ideias}

$81 \%$ Pouco ou nada fizemos para gerar novas ideias. $10 \%$ Tivemos ideias impostas por um ou dois membros do grupo. 9\% Nós encorajamos uns aos outros.

Garavit, J. 2021 
Aos membros do grupo em momentos distintos e nos quais cada aluno se expressa durante o trabalho coletivo. Os resultados fornecem indicadores climáticos. O grupo e o treinador podem traçar rotas de ação para melhorar a coesão e a produtividade. A Tabela 3.6 fornece um exemplo de resultados que indicam um problema de desempenho. Outros dispositivos menos especializados, como os mencionados acima para apoiar um sentimento de pertencimento, também podem ser usados para ajudar o grupo a alcançar uma melhor produtividade. Guias de tarefas, novas mensagens ou indicadores de novos documentos são formas que podem apoiar a produtividade, informando ao aluno o que precisa ser feito, o que foi feito e o que ainda não foi feito, o resto das coisas a fazer.

\section{Coordenação de grupo.}

A coordenação é para garantir a organização eficiente das atividades, pessoas e recursos para atingir uma meta. Em um contexto colaborativo, coordenar significa assumir a gestão de tarefas: dividir em subtarefas, atribuir responsabilidades, usar recursos, etc. É também administrar os aspectos emocionais e psicossociais do grupo: reconhecimento, apoio, incentivo, motivação, clima, etc. de todos. Para descrever o processo de coordenação em ambiente virtual, utilizamos a estratégia desenvolvida por Ricciardi-Rigault (1989), que se refere principalmente à organização do trabalho em grupo e à arquitetura de fóruns eletrônicos.

\section{A distribuição do trabalho do grupo}

Ricciardi-Rigault aponta três variáveis a controlar para melhor canalizar e coordenar as energias e atividades do grupo: 1) a tarefa, 2) a constituição e composição do grupo e 3) a animação.

\footnotetext{
A tarefa

Realizar uma tarefa colaborativa significa trabalhar em conjunto e ajudar-se mutuamente para que todos alcancem o objetivo que o grupo definiu na negociação e tendo em conta as expectativas de todos. A tarefa leva a uma produção concreta e envolve os três componentes do modelo de colaboração que apresentamos acima: comunicação, compromisso e coordenação. É dividido e organizado em três subtarefas genéricas, negociar, executar e gerenciar, que são mostradas na Tabela 3.7
} 
Tabela 3.7

Extração de tarefa

\begin{tabular}{|l|c|}
\hline \multicolumn{1}{|c|}{ Divisão de tarefas } & Componentes de colaboração. \\
\hline $\begin{array}{l}\text { Discutir, negociar para chegar a um acordo sobre o } \\
\text { projeto a ser realizado. }\end{array}$ & Comunicação de ideias. \\
\hline Realize o projeto trabalhando em conjunto. & Compromisso com o grupo. \\
\hline $\begin{array}{l}\text { Gerenciar a conclusão do projeto, definindo os } \\
\text { parâmetros materiais, temporais, espaciais e } \\
\text { organizacionais da obra. }\end{array}$
\end{tabular}

Garavit, J. 2021.

\section{O grupo e as equipes}

A constituição e composição do grupo ou equipes é uma etapa crítica que não deve ser esquecida para garantir o funcionamento ideal da colaboração. É um momento crítico e delicado que pode influenciar a motivação e o comprometimento. Por este motivo, é desejável que os alunos compreendam as escolhas que terão sido feitas quanto à constituição do grupo ou equipas. $\mathrm{O}$ grupo ou as equipes serão homogêneos? Quem será o encarregado de compô-los? Quão grandes eles serão? Qual método será adotado para distribuir os alunos em grupos ou equipes? O formador irá primeiro responder a estas questões considerando os dados sociodemográficos habituais dos alunos, os elementos contextuais, os objetivos de aprendizagem e o modelo de colaboração pretendido.

\section{Tabela 3.8}

\section{Constituição e composição de um grupo}

\begin{tabular}{|c|c|}
\hline $\begin{array}{l}\text { Constituição e composição } \\
\text { do Grupo ou Equipes }\end{array}$ & Aspectos a considerar \\
\hline $\begin{array}{c}\text { O grupo será heterogêneo ou } \\
\text { homogêneo? }\end{array}$ & $\begin{array}{l}\text { Depende dos aspectos que você deseja promover. } \\
\text { - Complementaridade, interdependência } \\
\text { - Coesão } \\
\text { - Produtividade }\end{array}$ \\
\hline $\begin{array}{l}\text { O treinador escolhe apenas os } \\
\text { membros do grupo e } \\
\text { equipes? } \\
\text { A escolha fica ao critério dos } \\
\quad \text { alunos? }\end{array}$ & $\begin{array}{l}\text { Depende do perfil dos alunos e do tempo disponível para reagrupamento. } \\
\text { - Autonomia } \\
\text { - Cultura Ambiental } \\
\text { - Limitações de tempo }\end{array}$ \\
\hline $\begin{array}{l}\text { Qual será o tamanho do } \\
\text { grupo: pequeno, médio ou } \\
\text { grande? }\end{array}$ & $\begin{array}{l}\text { Depende da tarefa. } \\
\text { - Discussão = grupos grandes }(25-30) \\
\text { - Realizando o projeto = grupos menores (equipes, } 3-5) \\
\text { - Gestão = grupos médios (menos de } 20) \\
\text { Depende do que se espera do grupo em termos de comprometimento, } \\
\text { participação. } \\
\text { - Quanto maior o grupo, menor é a pressão para se comprometer e participar. }\end{array}$ \\
\hline
\end{tabular}

Garavit, J. 2021 
Existem basicamente dois métodos de formação de grupos e equipes: atribuição ou livre escolha. Se os alunos se conhecem, estão acostumados a trabalhar em grupos e o tempo permite, geralmente é melhor deixá-los se encontrarem. Caso contrário, é melhor distribuir os alunos aleatoriamente. O tempo disponível para a realização da atividade colaborativa e o tipo de trabalho a ser realizado são fatores determinantes no método a ser adotado na formação do grupo (Abrami et al., 1995).

\section{Animações de grupo}

As animações eletrônicas do fórum desempenham um papel importante no sucesso da colaboração remota. Para cada fórum, a presença de um moderador é essencial; será necessário decidir quem vai desempenhar esse papel. Para cada grupo, será necessário escolher e planejar a estratégia de animação. O formador é o principal responsável pelas decisões a tomar em termos de animação. Você deve determinar a pessoa que animará as discussões ou trabalho e a estratégia de facilitação que será adotada. Porém, quanto mais autônomo o grupo, mais ele pode garantir sua própria animação. A Tabela 3.9 mostra três elementos desse problema que já apresentamos no segundo capítulo: funções e estratégias de facilitação, uma tipologia de intervenções e a escolha do moderador.

\section{Suporte a tarefas}

Tabela 3.9

Animação de fóruns eletrônicos

\begin{tabular}{|c|c|}
\hline $\begin{array}{l}\text { Elementos do problema de } \\
\text { animação do fórum }\end{array}$ & Itens de resposta \\
\hline $\begin{array}{l}\text { Quais funções e quais } \\
\text { estratégias de animação? }\end{array}$ & $\begin{array}{l}\text { - Anfitrião social } \\
\text { - Guia, facilitador, conselheiro, gerente } \\
\text { - Promoção da participação } \\
\text { - Apoio à motivação }\end{array}$ \\
\hline Quais intervenções? & $\begin{array}{l}\text { Feenberg (1989) sugere três tipos. } \\
\text { - Contextualização: contexto e estrutura da discussão, horário de trabalho, } \\
\text { modus operandi de trocas, procedimento, código de ética, etc. } \\
\text { - Acompanhamento: verificação da coesão e produtividade, reconhecimento } \\
\text { da participação, orientação da tarefa a ser realizada, etc. } \\
\text { - Metafunções: abertura e fechamento, resumo ou conclusão, ligações entre } \\
\text { subtarefas, ligações entre ideias (macroestrutura e microestrutura), etc. }\end{array}$ \\
\hline $\begin{array}{l}\text { Quem fará o papel de } \\
\text { moderador? }\end{array}$ & $\begin{array}{l}\text { Essa decisão é tomada com base no trabalho e no número do grupo. } \\
\text { - Para uma discussão na televisão com um grande grupo: o treinador } \\
\text { - Para gerenciamento remoto em um grupo médio: o treinador } \\
\text { - Para realizar o projeto em equipe: um aprendiz }\end{array}$ \\
\hline
\end{tabular}

Garavit, J. 2021

Todos os dispositivos que descrevemos acima contribuem para o suporte da tarefa. No entanto, do ponto de vista da coordenação, precisamos garantir que eles estejam disponíveis no momento 
certo (nem todos precisam estar permanentemente acessíveis) e no lugar certo. Para evitar confusão e desorientação, o ambiente deve estar evoluindo se for complexo. Deve ser transformado e acomodado à precariedade específica dos alunos. Definir o ambiente também deve ajudar o grupo a desenvolver uma visão compartilhada de colaboração, estimular o comprometimento e neutralizar os sentimentos de isolamento. Para isso, para uma determinada atividade ou tarefa, a interface deve permitir que o andamento dos trabalhos seja exibido automaticamente e os fóruns correspondentes indicados.

\section{A constituição do grupo e das equipes}

Dependendo do método escolhido para constituir o grupo, da comissão ou da livre escolha, as ferramentas podem variar. Aqui estão algumas ferramentas que podem apoiar a formação de grupos.

- Uma lista de membros do grupo que fornecem seus dados de contato e possivelmente seus dados sociodemográficos usuais - bastante útil para o método de alocação.

- Um cartão de visita que permite a cada um se apresentar: bastante útil para o método da livre escolha.

- Um indicador de presença online para facilitar e incentivar os contactos iniciais: bastante útil para o método da livre escolha.

\section{A animação do facilitador}

Para auxiliar o facilitador em sua tarefa, seja esta função desempenhada pelo treinador ou pelo aluno, o software do fórum eletrônico deve oferecer uma variedade de ferramentas de gestão para:

- Crie grupos;

- Abrir e fechar fóruns;

- Conceda privilégios e direitos de acesso;

- Acompanhar o andamento das trocas: conteúdo, dinâmica cognitiva e psicossocial;

- Estabeleça um cronograma e uma agenda;

- Crie formulários ou relatórios de acompanhamento de tarefas de andamento do trabalho;

- Desenvolver instrumentos de medição, votação e votação;

- Crie ferramentas para apoiar as decisões tomadas.

O facilitador deve ser adequado e capaz de combinar o uso de ferramentas de gestão com todas as demais presentes no ambiente: ferramentas de planejamento; medição sociométrica, análise do conteúdo das trocas, representação do conteúdo semântico; etc. As informações que o facilitador obtém desses diversos recursos irão ajudá-lo a avaliar o desempenho do grupo, fazer diagnósticos e decidir o tipo de intervenção apropriada para cada situação. 


\section{Estrutura de um espaço de comunicação}

A estrutura do espaço de comunicação que apresentamos preserva cinco tipos principais de fóruns, cada um com as suas características e vocação próprias: tele-discussão, teletrabalho, telegestão, tele-assistência e tele-socialização. Dentre elas, aqui estamos mais especificamente interessados nas três espécies que se relacionam com a tarefa cognitiva: teletrabalho, teletrabalho e telegestão. A tele discussão é usada para apoiar trocas intelectuais (debate, desenvolvimento de um tema, desenvolvimento de hipóteses, etc.) que terão uma conclusão dentro do próprio fórum.

Tabela 3.10

Trabalho de casa, tamanho do grupo e animação

\begin{tabular}{|c|c|c|c|}
\hline Variável. & Tele Discussion. & Teletrabalho & Gerenciamento remoto. \\
\hline Mancha. & $\begin{array}{l}\text { Discuta para alimentar um } \\
\text { projeto, comum ou não, que } \\
\text { será feito fora do fórum. }\end{array}$ & $\begin{array}{l}\text { Realizar um projeto } \\
\text { conjunto, dentro do } \\
\text { fórum. }\end{array}$ & $\begin{array}{l}\text { Comunique as instruções. } \\
\text { Decida sobre a logística. } \\
\text { Monitore todo o processo. }\end{array}$ \\
\hline $\begin{array}{l}\text { Tamanho } \\
\text { do grupo. }\end{array}$ & $\begin{array}{c}\text { Maior grupo (máximo de } 20 \\
\text { a 30) }\end{array}$ & Grupo pequeno (3 a 5) & Grupo médio (máximo de 20) \\
\hline Animação. & Pelo treinador & Por alunos & Pelo treinador \\
\hline
\end{tabular}

Garavit, J. 202

Tabela 3.11

Recursos de colaboração

\begin{tabular}{|c|c|c|}
\hline $\begin{array}{l}\text { Componentes } \\
\text { de colaboracão }\end{array}$ & O grupo como recurso & Recursos tecnológicos no fórum e periferia \\
\hline $\begin{array}{l}\text { Comunicação } \\
\text { Ideias } \\
\text { Microestrutura } \\
\text { Macroestrutura }\end{array}$ & $\begin{array}{l}\text { É importante que o aluno } \\
\text { possa: } \\
\text { Expresse e comunique suas } \\
\text { idéias livremente. } \\
\text { Obtenha novas ideias. } \\
\text { Faça conexões entre ideias } \\
\text { para desenvolver conceitos. } \\
\text { Construa seu próprio } \\
\text { conhecimento. }\end{array}$ & $\begin{array}{l}\text { Ferramenta para ajudar a estruturar mensagens. } \\
\text { Ferramenta para ajudar a estruturar a discussão em } \\
\text { função da tarefa (atividade cognitiva, socialização, } \\
\text { coordenação). } \\
\text { Visualização da organização de fóruns. } \\
\text { Visualizar todas as mensagens para sua leitura é essencial } \\
\text { (promova a participação). } \\
\text { Visualizando links entre mensagens. } \\
\text { De qualquer lugar do ambiente, identificação rápida e fácil do } \\
\text { fórum para participar para postar uma mensagem. } \\
\text { Acesso ao resumo da mensagem. } \\
\text { Acesso e recuperação de informações usando ferramentas para } \\
\text { pesquisar o texto de mensagens e outros documentos. } \\
\text { Ferramenta de hipertexto para criar links. } \\
\text { Ferramenta de anotações pessoais. } \\
\text { Hesident local para manipulação offline. }\end{array}$ \\
\hline
\end{tabular}

Garavit, J. 2021

Também serve para debater e alimentar um projeto que será realizado fora do fórum, em outros espaços. O fórum do teletrabalho é o local onde os projetos conjuntos são realizados de forma 
eficaz. A telegestão é utilizada para a comunicação de instruções, decisões relativas à organização e logística da tarefa e para o acompanhamento de todo o processo. A Tabela 3.10 mostra os três tipos de fóruns relacionados à alocação, número de membros do grupo e facilitação.

Tabela 3.11

\section{Recursos de colaboração (continuação)}

\begin{tabular}{|c|c|c|}
\hline $\begin{array}{l}\text { Componentes de } \\
\text { colaboração }\end{array}$ & O grupo como recurso & Recursos tecnológicos no fórum e periferia \\
\hline $\begin{array}{l}\text { Compromisso } \\
\text { Cognitivo. } \\
\text { Emocional } \\
\text { social }\end{array}$ & $\begin{array}{l}\text { Para garantir uma colaboração } \\
\text { efetiva, os membros de um grupo } \\
\text { de alunos devem atingir um alto } \\
\text { nível de realização, coesão social e } \\
\text { produtividade intelectual. } \\
\text { No plano socioemocional, pode- } \\
\text { se estabelecer um clima de } \\
\text { confiança e eliminar as fontes de } \\
\text { ansiedade. }\end{array}$ & $\begin{array}{l}\text { Analisador de rastreamento. } \\
\text { História (quem leu o quê e quando. Quem fez o quê, } \\
\text { quando e como). } \\
\text { Instrumentos de medição automatizados para coesão e } \\
\text { produtividade. } \\
\text { Gerador de estatísticas (índices de produtividade e } \\
\text { coesão, por exemplo). } \\
\text { Lista de participantes e seus currículos. } \\
\text { Visualização da dinâmica das trocas (comunicado, } \\
\text { sociograma). }\end{array}$ \\
\hline $\begin{array}{l}\text { Coordenação } \\
\text { Discussão tele. } \\
\text { Teletrabalho. } \\
\text { Gerenciamento } \\
\text { remoto. }\end{array}$ & $\begin{array}{l}\text { A organização e o gerenciamento } \\
\text { das atividades, tanto em grupos } \\
\text { grandes como pequenos, devem } \\
\text { ser facilitados para que o } \\
\text { aprendizado seja fluido e eficaz. }\end{array}$ & $\begin{array}{l}\text { Criação e gestão fácil e eficiente de fóruns. } \\
\text { Arquivo e recuperação de informações. } \\
\text { Ferramentas de planejamento e ferramentas genéricas } \\
\text { de monitoramento (diário de bordo, relatório de } \\
\text { andamento da obra, cronograma, etc.). } \\
\text { Ferramentas de decisão (pesquisa, voto). }\end{array}$ \\
\hline
\end{tabular}

Garavit, J. 2021

É sobretudo a interface que entra em jogo na representação dos locais de comunicação. O aluno deve ser capaz de identificar facilmente a qual fórum se inscrever para a tarefa em questão. Uma interface simples deve permitir um fácil reconhecimento da forma como os fóruns são organizados. Para as tele-discussões, procurar-se-á mostrar a estrutura do tema ou objeto de discussão: linear, arborescente, paralelo, etc. Para o gerenciamento remoto, é necessário identificar o objeto ao qual o gerenciamento se refere. Finalmente, para o teletrabalho, cada equipe deve ser capaz de localizar o local de trabalho reservado para eles. A Tabela 3.11 fornece uma lista de recursos colaborativos que encontram seu lugar em um ambiente de aprendizagem virtual. Colocamos eles em contato com os componentes do nosso modelo de colaboração. 


\section{Referências}

Abrami, P., Chambers, P., Poulsen, C., De Simone, C., D 'Apollonia, S. e Howden, J. (1995). Conexões na sala de aula: entendendo e usando a aprendizagem cooperativa. Toronto, Harcourt Brace \& Company.

Ackerman, MS (1996). Proporcionar interação social na biblioteca digital. Na CSCW '96, Conferência sobre Trabalho Auxiliado por Computador, Association for Computing Machinery.

Bonk, CJ e King, KS (1995). Aulas de computador e ferramentas de escrita colaborativa: iniciar um diálogo sobre o diálogo do aluno.

Collings, P. et Walker, D. (1995). Aplicativos de apoio ao trabalho em grupo de alunos. Dans CSCL '95 Proceedings, Faculdade de Ciência da Informação e Engenharia, Universidade de Canberra, Austrália, outubro.

Damphousse, L. (1996). Participação e animação: um modelo de análise da teleconferência assistida por computador na TV Universitária. Dissertação de mestrado em comunicação, Universidade de Quebec a Montreal.

Deschénes, AJ (1995). Rumo a um modelo construtivista de produção textual. Em Boyer, JY, Dionne, JP, Raymond, P. A produção de textos. Montreal, Edições lógicas.

Dimock, HG (1985). Como analisar e avaliar o crescimento do grupo. 2e ed., Guelph, University of Guelph.

Dimock, HG (1987). Projetar e facilitar programas de treinamento. $4^{\mathrm{a}}$ ed., Guelph, University of Guelph.

Garavit, J. (2017) projeto de um objeto virtual de aprendizagem na UNAD, para fortalecer os processos de aprendizagem do curso de Lógica Matemática na modalidade a distância. https://doi.org/10.13140/RG.2.2.35320.39687

Garavit, J. (2021f). Livro de Métodos Interativos para Educação: Transformando a América Latina na Era Digital, Págs. 277 - 329 ISBN: 978-958-49-2799-6

Garavit, J. (2021 g). Desafios e padrões variáveis da Educação a Distância e Blended Learning Livro: Transformando a América Latina na Era Digital, Págs. 364-382 ISBN: 978-958-492799-6

Gutwin, C., Stark, G. e Greenberg, S. (1995). Apoio à conscientização do espaço de trabalho de groupware educacional.

Guzdial, M., Turns, J., Rappin, N. e Carlson, D. (1995). Suporte colaborativo para aprendizagem em domínios complexos.

Hoadley, CM e HSI, S. (1993). Uma interface multimídia para construção de conhecimento e aprendizagem colaborativa. Proceedings of Inter CHI 93, ACM SIG-CHI e conferência Interact, Amsterdam, The Netherlands, April 24-29, 1993. ACM Press.

Kagan, S. (1992). Aprendizado cooperativo. San Juan Capistrano, Ca., Recursos para professores. 
Klemm, WR et Snell, JR (1996). Enriquecimento da aprendizagem em grupo, combinando o construtivismo com a aprendizagem colaborativa.

Lundgren, K. (1996). Conferência por Computador: Um Ambiente de Aprendizagem Colaborativa para Alunos de Educação a Distância. Tese de doutorado, Montreal, Concordia University.

Mullen, B. e Copper, C. (1994). A relação entre coesão de grupo e desempenho: uma integração. Boletim psicológico.

Paquin, C. (1993). Análise exploratória para o uso de tecnologia de repositório em um ambiente de desenvolvimento de material de treinamento. Dissertação de mestrado em informática para negócios. Montreal, Universidade de Quebec em Montreal.

Ricciardi Rigault, C. e Henri, F. (1989). Apoio à aprendizagem. Anais do colóquio. Transferência de conhecimento em ciência e tecnologia. Universidade de Montpellier II.

Roscheisen, M., Mogensen, C. e Winograd, T. (1996). Além da navegação: comentários compartilhados, SOAP (selos de aprovação), trilhas e comunidades online.

Schragé, M. (1990). Mentes compartilhadas. Novas tecnologias de colaboração. Nova York, Random House.

Schroeder, EE e Kenny, RF (1995). Estratégias de aprendizagem para instrução multimídia interativa: Aplicação de anotações lineares e espaciais. Canadian Journal of Educational Communication.

St-Arnaud, Y. (1989). Pequenos grupos. Participação e comunicação. Editoras da Universidade de Montreal e Les Éditions du CMI. 